\title{
A Critical Approach to Administration of Low-Dose Aspirin (LDA) to Improve Implantation Success
}

\author{
Seyyed Amir Yasin Ahmadi ${ }^{*}$, Majid Tavafi , Pary Sadat Ahmadi ${ }^{3}$
}

\section{Dear Editor,}

Infertility has many causes and different pathogenesis, and there are some critical controversies against most of its therapeutic protocols. Some researchers showed that low-dose aspirin (LDA) has positive effect on ovary, fertilization and implantation for users of assisted reproductive technology (ART) such as in-vitro fertilization (IVF); but such researches are not enough and need to be investigated further. As opposed to the mentioned hypothesis, Akhtar et al (1)announced that: "Adjuvant treatment with aspirin and heparin do not improve IVF outcome." After a year, Salvatore Gizzo as a fan and defender of LDA administration announced that empirical administration without protocol can cause negative effects. He is of the conviction that LDA can increase uterine blood flow, vasodilatory and spiral artery remodeling and inhibits platelet aggregation (2). Finally we want to announce that the negative connotation of the words like inflammation, apoptosis and natural killer is not a reason that inhibiting such physiological phenomenon is always a good method. In Gizzo et al (2) research total number of follicles, size of follicles and number of mature oocytes were significantly increased after LDA administration and number of good quality embryos were decreased; but in spite of this decreasing he insisted on his hypothesis. The criticisms against the fans of LDA fall into these items. First, some of these papers used the mice dose $7.5 \mathrm{mg} / \mathrm{kg} 2$ times a day, but they neither performed the pilot dose-assaying examination (in 4 groups: low dose, high dose, toxic dose and killing dose) nor cited the reason of using this number. Based on the Food and Drug Administration (FDA) guideline (3) their selected dose $(15 \mathrm{mg} / \mathrm{kg})$ is equivalent to human routine low dose $81 \mathrm{mg}$ (of course in a $66.9 \mathrm{~kg}$ person) (Table 1), but it seems they employed this correct dose number only out of imitation from each other. Second, aspirin even in low dose may cause side effects.

Table 1. How to Convert Mice Dose to Human

\begin{tabular}{ll}
\hline Organism & Proportion \\
\hline Mice $\mathrm{mg} / \mathrm{kg}$ & 37 \\
Human $\mathrm{mg} / \mathrm{kg}$ & 3 \\
\hline
\end{tabular}

Third, the reproductive system of the mice and rat is not sufficiently similar to human system. Forth, the inflammation of endometrium during luteal phase is per se a helping phenomenon for implantation, so it is not a logical idea for research proposals to use anti-inflammatory drugs.

Inoue et al (4) said that inhibition of natural-killer cells $(\mathrm{NK})$ - with aspirin or prednisolone - results in better interface between embryo and maternal tissue (4) with citing the reference (5); but Clifford et al (5) believed alteration - stimulating or inhibiting - in population of NKs causes failure in early pregnancy and needs more investigation. Also, Inoue et al (4) cited the reference (6); but the mentioned reference had found no significant relation between placebo and LDA group. Haapsamo et al (6) have done the research based on the conviction that LDA can improve remodeling of spiral arteries; but it seems wrong; because decidual NKs improve remodeling of spiral arteries (7) through increasing IFN-Gamma and TNF-alpha (8). Also IFN-gamma is an apoptosis inducer (9) which seems necessary for implantation period; but the author of reference (9) counts this feature as a harmful process. It be noted that apoptosis is per se physiologic and not pathologic most of the times.

At the end of the letter we notify that designing a correct hypothesis and a valid protocol is a sine qua non. Regarding the review data, our thought is that LDA may have positive effects on ovary and negative effects on endometrium. Thus very short-term administration of LDA (only at the time of ovulation) should be performed in future researches.

\section{References}

1. Akhtar MA, Eljabu H, Hopkisson J, Raine-Fenning N, Quenby S, Jayaprakasan K. Aspirin and heparin as adjuvants during IVF do not improve live birth rates in unexplained implantation failure. Reprod Biomed Online 2013;26(6):586-94. doi: 10.1016/j. rbmo.2013.02.007.

2. Gizzo S, Capuzzo D, Zicchnia C, et al. Could empirical low-dose-aspirin administration during IVF cycle

Received 15 April 2015, Accepted 9 July 2015, Available online 1 October 2015

${ }^{1}$ Student Research Committee, Lorestan University of Medical Sciences, Khorramabad, Iran. ${ }^{2}$ Department of Anatomy, Lorestan University of Medical Sciences, Khorramabad, Iran. ${ }^{3}$ Student Research Committee, Iran University of Medical Sciences, Tehran, Iran.

*Corresponding author: Seyyed Amir Yasin Ahmadi, Student Research Committee, Lorestan University of Medical Sciences, Khorramabad, Iran. Tel: +989392838309, Email: yasin_ahmadi73@yahoo.com 
affect both the oocytes and embryos quality via COX 1-2 activity inhibition? J Assist Reprod Genet. 2014;31(3):261-268.

3. Guide for industry estimating the maximum safe starting dose in initial clinical trials therapeutics in adult healthy volunteers. FDA website. http://www.fda. gov/downloads/food/ingredients packaginglabeling/ gras/noticeinventory/ucm277372. Published July 2005.

4. Inoue $\mathrm{T}$, Ono $\mathrm{Y}$, Yonezawa $\mathrm{Y}$, Kishi J, Emi N. Improvement of live birth rate following frozenthawed blastocyst transfer by combination of prednisolone administration and stimulation of endometrium embryo transfer. Open J Obstet Gynecol. 2014;4(13):49531. doi:10.4236/ ojog.2014.413103.

5. Clifford K, Flanagan AM, Regan L. Endometrial CD56+ natural killer cells in women with recurrent miscarriage: a histomorphometric study. Hum Reprod. 1999;14(1):2727-2730.

6. Haapsamo M, Martikainen $H$, Tinkanen $H$, Heinonen S, Nuojua-Huttunen S, Räsänen J. Low- dose aspirin therapy and hypertensive pregnancy complications in unselected IVF and ICSI patients: a randomized, placebo-controlled, double-blind study. Hum Reprod. 2010;25(12):2972-2977. doi: 10.1093/ humrep/deq286.

7. Fraser R, Whitley GS, Thilaganathan B, Cartwright JE. Decidual natural killer cells regulate vessel stability: implications for impaired spiral artery remodeling. J Reprod Immunol. 2015;110:54-60. doi: 10.1016/j. jri.2015.04.003.

8. Chen CP, Piao L, Chen X, et al. Expression of interferon $\gamma$ by decidual cells and natural killer cells at the human implantation site implications for preeclampsia, spontaneous abortion, and intrauterine growth restriction. Reprod Sci. 2015 May 11. pii: 1933719115585148.

9. Zhang L, Zhao M, Jiao F, et al. Interferon gamma is involved in apoptosis of trophoblast cells at the maternal-fetal interface following Toxoplasma gondii infection. Int J Infect Dis. 2015;30:10-16. doi: 10.1016/j.ijid.2014.10.027.

Copyright (C) 2015 The Author(s); This is an open-access article distributed under the terms of the Creative Commons Attribution License (http://creativecommons.org/licenses/by/4.0), which permits unrestricted use, distribution, and reproduction in any medium, provided the original work is properly cited. 